\title{
江苏省优质软麦品种品质特性与饼干加工品质的关系
}

\author{
张平平姚金保王化敦宋桂成姜朋张鹏 马鸿翔“
}

江苏省农业科学院粮食作物研究所 / 江苏省现代作物生产协同创新中心, 江苏南京 210014

摘 要: 明确软麦品种在大田生产中的品质表现和品质育种篮选指标, 对于优质生产及提高育种效率具有重要意 义。选用江苏淮南麦区 15 份优质软麦品种(系), 鉴定其高分子量麦谷蛋白亚基(HMW-GS)组成, 开展 3 个试验点次的 大田种植, 分析了小麦样本的籽粒硬度、灰分含量、蛋白质含量和质量参数、粉质仪参数、揉面仪参数、溶剂保持 力、䛎藏蛋白组分含量参数、黏度仪参数等品质性状和饼干加工品质。结果表明, 不同类型的品质参数受基因型和 环境的影响不同。所有样本的蛋白质含量、湿面筋含量、稳定时间均不达国标(GB/T 17320-2013、GB/T 17893-1999), 部分品种(系)的沉淀值达标, 所有样本的籽粒硬度和吸水率全部达标。相关性分析表明, 籽粒硬度、灰分含量和黏度 仪参数与饼干加工品质无显著相关性。沉淀值、粉质仪吸水率、粉质仪稳定时间、揉面仪峰值时间、揉面仪衰落角、 水溶剂保持力、碳酸钠溶剂保持力、乳酸溶剂保持力、谷蛋白/醇溶蛋白比、不溶性谷蛋白含量和不溶性谷蛋白百分 含量与饼干直径呈显著 $(r \leq-0.520)$ 或极显著 $(r \leq-0.652)$ 负相关, 相关系数分别为 $-0.657 、-0.601 、-0.617 、-0.659$ 、 $-0.676 、-0.857 、-0.726 、-0.616 、-0.546 、-0.541$ 和 -0.637 。多元回归方程显示，水溶剂保持力可解释饼干直径变异 的 $73.76 \%$, 与籽粒蛋白共同可解释饼干直径变异的 $83.90 \%$ 。在籽粒硬度和蛋白含量选择的基础上, 降低面筋强度和 面粉综合吸水特性是软麦育种的主要目标, 水溶剂保持力、乳酸溶剂保持力和揉面仪参数是软麦育种最重要的篮选 指标。

关键词：普通小麦; 江苏; 优质软麦; 品质特性; 饼干品质

\section{Soft wheat quality traits in Jiangsu province and their relationship with cookie making quality}

ZHANG Ping-Ping, YAO Jin-Bao, WANG Hua-Dun, SONG Gui-Cheng, JIANG Peng, ZHANG Peng, and MA Hong-Xiang ${ }^{*}$

Institute of Food Crops, Jiangsu Academy of Agricultural Sciences / Jiangsu Collaborative Innovation Center for Modern Crop Production, Nanjing 210014, Jiangsu, China

\begin{abstract}
The objectives of this study were to investigate soft wheat quality traits with fertilizer management practice in southern region of the Huaihe river in Jiangsu province, and to suggest quality selection parameters in soft wheat breeding. Fifteen high quality soft wheat varieties or advanced lines were grown at three environments with the combination of location and year. High-molecular-weight glutenin subunits (HWM-GS) of tested genotypes were identified. Kernel hardness, grain and flour protein content, wet gluten content, ash content, Zeleny sedimentation value, parameters of farinograph, mixograph, and rapid viscocity analysis (RVA), solvent retention capacity (SRC), gluten protein quantification, and cookie quality were investigated. No sample met the national soft wheat quality standard (GB/T 17320-2013, GB/T 17893-1999) for protein content, wet gluten content, and
\end{abstract}

\footnotetext{
本研究由江苏省重点研发计划(现代农业)子项目(BE2018399-1), 江苏省自然科学基金项目(BK20161375), 国家自然科学基金项目 (31671690)，江苏省自主创新资金项目(CX(18)1001)和国家现代农业产业技术体系建设专项(CARS-03)资助。

This study was supported by the Key Project for the Research and Development of Jiangsu Province (BE2018399-1), the Natural Science Foundation of Jiangsu Province (BK20161375), the National Natural Science Foundation of China (31671690), the Indigenous Innovation Foundation of Jiangsu Provincial Agricultural Science and Technology (CX(18)1001), and the China Agriculture Research System (CARS-03).

* 通信作者(Corresponding author): 马鸿翔, E-mail: hxma@jaas.ac.cn

第一作者联系方式: E-mail: pp_zh@126.com
}

Received (收稿日期): 2019-08-07; Accepted (接受日期): 2019-12-26; Published online (网络出版日期): 2020-01-15.

URL:http://kns.cnki.net/kcms/detail/11.1809.S.20200115.0940.006.html 
farinograph stability, few samples met the standard for sedimentation value, and all samples exceeded the standard for kernel hardness and farinograph absorption. Kernel hardness, ash content, and RVA parameters were not significantly associated with cookie quality parameters. Zeleny sedimentation value, absorption and stability of farinograph, peak time and right of peak slope of mixograph, water SRC, sodium carbonate SRC, lactic acid SRC, glutenin/gliadin ratio, unextractable polymeric protein (UPP), and \%UPP were significantly correlated with cookie diameter, with $r=-0.657,-0.601,-0.617,-0.659,-0.676$, $-0.857,-0.726,-0.616,-0.546,-0.541$, and -0.637 , respectively $(r \leq-0.520, P<0.05 ; r \leq-0.652, P<0.01)$. One multiple regression model only with water SRC as a variable could explain $73.76 \%$ of the total variation of cookie diameter, and the other regression model with both water SRC and kernel protein content as variables could explain $83.90 \%$ of the total variation. Based on the selection of grain hardness and protein content, reducing gluten strength and general water holding capacity is the main targets in soft wheat breeding program, and water SRC, lactic acid SRC and mixograph parameters are the most important selection parameters.

Keywords: common wheat; Jiangsu province; high quality soft wheat; quality traits; cookie quality

江苏淮南麦区是我国优质软麦(弱筋小麦)核心 产区，九五以来多个优质软麦品种培育成功 ${ }^{[1-3]}$ 。但 软麦需求量逐年提高与抽样达标率不断降低的矛盾 日益突出 ${ }^{[4-5]}$ 。软麦品种高产栽培与加工品质矛盾大, 在大田生产中的品质表现仍不明确 ${ }^{[6-7]}$, 软麦育种仍 以农艺性状和籽粒表型选择为主, 高效品质选择方 法仍未广泛应用。现行国家标准对品种或原粮品质 鉴定以小麦籽粒硬度和粗蛋白含量为基本指标, 同 时规定了面粉湿面筋含量、Zeleny 沉淀值、粉质仪吸 水率和稳定时间等面粉理化和面团特性等指标 ${ }^{[8-10]}$ 。

籽粒硬度、蛋白含量与软麦加工品质的关系较为明 确, 一般呈负相关 ${ }^{[2]}$ 。湿面筋含量主要由蛋白质含量 决定, 也受蛋白质质量的影响 ${ }^{[11]}$ 。沉淀值综合反映 蛋白质质量和数量, 测试方法快速低廉, 是应用最 广泛的品质育种篮选指标之一 ${ }^{[12-13]}$ 。粉质仪稳定时 间和吸水率皆与软麦加工品质密切相关 ${ }^{[1]}$, 但用粉 量大、工作效率低, 仅可用于育成品系的评价。另 外, 咜藏蛋白质量和数量 ${ }^{[14]}$ 、溶剂保持力 ${ }^{[1-3]}$ 、面粉 黏度仪分析 ${ }^{[1-2]}$ 、吹泡仪分析 ${ }^{[1,15]}$ 等品质鉴评方法在 软质小麦评价中的应用均有报道, 其中溶剂保持力 与软麦加工品质的关系尤为重要。但当被测试材料 的蛋白质含量和籽粒硬度差异较小时, 哪些指标快 速有效仍不明确。Zhang 等 ${ }^{[16]}$ 和张平平等 ${ }^{[3]}$ 对低蛋白 软麦的分类统计就表明, 籽粒硬度和蛋白含量与加 工品质无显著相关性, 这无疑增加了育种早代选择 的难度。本研究选用九五以来江苏淮南麦区选育的 优质软麦品种和高代品系, 以大面积生产的肥料管 理方法种植, 对小麦样本进行多种微量品质测试和 粉质仪测定, 同时进行饼干加工评价, 旨在了解这 些软麦品种(系)大田生产中的品质特性, 篮选软麦 加工品质预测指标。

\section{1 材料与方法}

\section{1 试验设计}

选用 1995-2010 年间的 7 份大面积推广的优质 软麦品种, 8 份高代优质软麦品系 ${ }^{[2]}$ (表 1$)$, 这些品系 基本代表了江苏淮南麦区软麦的品质状况。

于2013-2014年在江苏省农业科学院南京基地, 2013-2015年在江苏省农业科学院六合基地进行田 间试验, 试验地前茬分别为玉米和大豆, 共3个试验 点次。3 点次试验播前耕层土壤 $(0 \sim 20 \mathrm{~cm})$ 有机质 $13.2 \sim 22.5 \mathrm{~g} \mathrm{~kg}^{-1}$ 、全氮 $0.86 \sim 1.23 \mathrm{~g} \mathrm{~kg}^{-1}$ 、速效磷 $18.1 \sim 25.3 \mathrm{mg} \mathrm{kg}^{-1}$ 、速效钾 $65.4 \sim 88.6 \mathrm{mg} \mathrm{kg}^{-1}$ 。采用 随机区组设计, 2 次重复, 5 个行区, 行长 $1.6 \mathrm{~m}$, 行距 $26.7 \mathrm{~cm}$ 。适期播种, 基本苗 $2.10 \times 10^{6}$ 株 $\mathrm{hm}^{-2}$, 每个 生育期总施氮量为 $225 \mathrm{~kg} \mathrm{hm}^{-2}$ 纯氮, 设基肥: 苗 肥: 拔节肥为 $5: 2: 3$; 磷肥 $\left(\mathrm{P}_{2} \mathrm{O}_{5}\right)$ 和钾肥 $\left(\mathrm{K}_{2} \mathrm{O}\right)$ 总 施用量均为 $105 \mathrm{~kg} \mathrm{hm}^{-2}$, 设基肥: 拔节肥为 7 : 3 。生 育期田间管理同当地大田生产, 及时防治病虫草害, 成熟期分区收获并清理籽粒样本, 无穗发芽发生。 为了减少工作量及提高制粉量, 将经清理的 2 个重 复的种子等量混合作为最终试验籽粒样本。

\section{2 品质性状测定}

按AACC 55-31 ${ }^{[17]}$ 用单籽粒谷物测定仪(SKCS 4100, Single Kernel Characteristic System, Perten Instrument North America Inc., Reno, NV, USA)测定籽 粒硬度值HI(Hardness Index), 数值越大硬度越高, $<44$ 均为软麦, 其中 $35 \sim 44$ 为中软, $25 \sim 34$ 为软, 10 24 为很软, $<10$ 为超软。因所有样本均为软质麦(多数样 本 $<35$ ), 将籽粒样本调整至含水量 $13.5 \%$, 润麦 18 22 h, 按AACC 26-50 ${ }^{[17]}$ 用Branberder Quadrumat Jr. 实验磨制粉, 出粉率为 $62 \% \sim 67 \%$ 。按 NY/T 3-1982 《谷物豆类作物种子粗蛋白质测定法(半微量凯氏 
表 1 参试品种(系)及高分子量麦谷蛋白亚基组成

Table 1 HMW-GS composition of tested varieties or advanced lines

\begin{tabular}{|c|c|c|c|c|c|}
\hline $\begin{array}{c}\text { 品种(系) } \\
\text { Variety (line) }\end{array}$ & $\begin{array}{c}\text { 系谱 } \\
\text { Pedigree }\end{array}$ & Glu-A1 & Glu-B1 & Glu-D1 & $\begin{array}{l}\text { 黑麦易位系 } \\
\text { Secalin }\end{array}$ \\
\hline $\begin{array}{l}\text { 宁麦 } 8 \text { 号 } \\
\text { Ningmai } 8\end{array}$ & $\begin{array}{l}\text { 扬麦 } 5 \text { 号/扬麦 } 6 \text { 号 } \\
\text { Yangmai 5/Yangmai } 6\end{array}$ & Null & $7+9$ & $5+10$ & No \\
\hline $\begin{array}{l}\text { 宁麦 } 9 \text { 号 } \\
\text { Ningmai } 9\end{array}$ & $\begin{array}{l}\text { 扬麦 } 6 \text { 号/西凤 } \\
\text { Yangmai 6/Xifeng }\end{array}$ & 1 & $7+8$ & $2+12$ & No \\
\hline $\begin{array}{c}\text { 生选 } 6 \text { 号 } \\
\text { Shengxuan } 6\end{array}$ & $\begin{array}{l}\text { 宁麦 } 8 \text { 号/宁麦 } 9 \text { 号 } \\
\text { Ningmai 8/Ningmai } 9\end{array}$ & 1 & $7+8$ & $2+12$ & No \\
\hline $\begin{array}{l}\text { 扬麦 } 9 \text { 号 } \\
\text { Yangmai } 9\end{array}$ & $\begin{array}{l}\text { 扬鉴 3/扬麦 } 5 \text { 号 } \\
\text { Yangjian 3/ Yangmai } 5\end{array}$ & Null & $7+9$ & $2+12$ & No \\
\hline $\begin{array}{c}\text { 扬麦 } 13 \\
\text { Yangmai } 13\end{array}$ & $\begin{array}{l}\text { 扬 88-84//MarisDove/扬麦 } 3 \text { 号 } \\
\text { Yang 88-84//MarisDove/Yangmai } 3\end{array}$ & Null & $7+8$ & $2+12$ & No \\
\hline $\begin{array}{c}\text { 扬麦 } 15 \\
\text { Yangmai } 15\end{array}$ & $\begin{array}{l}\text { 扬 89-40/川㕕 } 21526 \\
\text { Yang 89-40/Chuanyu } 21526\end{array}$ & 1 & $7+8$ & $2+12$ & No \\
\hline $\begin{array}{c}\text { 扬麦 } 20 \\
\text { Yangmai } 20\end{array}$ & $\begin{array}{l}\text { 扬麦 } 9 \text { 号/扬麦 } 10 \text { 号 } \\
\text { Yangmai 9/Yangmai } 10\end{array}$ & Null & $7+9$ & $2+12$ & No \\
\hline 0864 & $\begin{array}{l}\text { 宁麦 } 8 \text { 号/宁 } 0021^{*} \\
\text { Ningmai 8/Ning } 0021^{*}\end{array}$ & 1 & $7+8 / 7+9$ & $2+12$ & No \\
\hline 0865 & $\begin{array}{l}\text { 宁麦 } 8 \text { 号/宁 } 0076^{*} \\
\text { Ningmai 8/Ning } 0076^{*}\end{array}$ & Null & $7+9$ & $5+10$ & No \\
\hline 0873 & $\begin{array}{l}\text { 扬麦 } 9 \text { 号/宁 } 0021 \\
\text { Yangmai 9/Ning } 0021\end{array}$ & Null & $7+8$ & $2+12$ & No \\
\hline 0874 & $\begin{array}{l}\text { 扬麦 } 9 \text { 号/宁 } 0021 \\
\text { Yangmai 9/Ning } 0021\end{array}$ & 1 & $7+8$ & $2+12$ & No \\
\hline 0876 & $\begin{array}{l}\text { 扬麦 } 9 \text { 号/宁 } 0021 \\
\text { Yangmai 9/Ning } 0021\end{array}$ & 1 & $7+8$ & $2+12$ & No \\
\hline 0893 & $\begin{array}{l}\text { 宁麦 } 13^{*} / \text { 宁麦 } 8 \text { 号//宁 } 0021 \\
\text { Ningmai } 13^{*} / \text { Ningmai 8//Ning } 0021\end{array}$ & Null & $7+8$ & $2+12$ & No \\
\hline 0894 & $\begin{array}{l}\text { 宁麦 } 9 \text { 号/宁 } 0021 \\
\text { Ningmai 9/Ning } 0021\end{array}$ & Null & $7+8$ & $2+12$ & No \\
\hline 08107 & $\begin{array}{l}\text { 宁麦 } 8 \text { 号/宁麦 } 13 \\
\text { Ningmai 8/Ningmai } 13\end{array}$ & 1 & $7+8$ & $5+10$ & No \\
\hline
\end{tabular}

*宁 0021、宁 0076 和宁麦 13 均为宁麦 9 号选系。

*Ning 0021, Ning 0076, and Ningmai 13 were bred by pedigree selection method from Ningmai 9.

法)》测定籽粒蛋白质含量。按GB/T 14608-1993《小 麦粉湿面筋测定法(洗面筋仪洗涤法)》测定湿面筋含 量。按 GB/T 21119-2007《小麦沉淀指数测定Zeleny 试验》测定沉淀值。用近红外分析仪(DA7200, Perten Instrument North America Inc., Springfield, IL, USA) 面粉灰分定标模型测定灰分含量。按 GB/T 358662018 微量法测定4种溶剂保持力 (solvent retention capacity, SRC), 分别为水溶剂保持力 (water SRC), 碳酸钠溶剂保持力 (sodium carbonate SRC), 乳酸溶 剂保持力 (lactic acid SRC) 和蔗糖溶剂保持力 (sucrose SRC)。按AACC 54-40 $0^{[17]}$ 用 $10 \mathrm{~g}$ 微量揉面仪 (National Manufacturing, Lincoln, NE)测定面团的揉 面特性, 记录峰值时间、峰值高度、衰落角和8分钟 带宽。按GB/T 14614-2006《小麦粉面团的物理特性 吸水量和流变学特性的测定粉质仪法》(东方孚德
JFZD，北京)测定面团揉混特性，记录形成时间、稳 定时间、吸水率和弱化度。

\section{3 糖酥饼干加工品质分析}

按 AACC 10-52 ${ }^{[17]}$ 糖酥饼干制作和评价方法, 记录 2 块饼干直径和厚度, 其配方中的糖为欴欢牌 烘焙用糖粉(C\&H, USA)。

\subsection{HMW-GS 组成分析和咜藏蛋白组分定量 分析}

参考 Liu 等 ${ }^{[18]}$ 的聚丙烯酰胺凝胶电泳 (SDSPAGE)方法鉴定HMW-GS组成，参考 Larroque等 ${ }^{[19]}$ 的凝胶色谱 (SE-HPLC)方法定量面粉的醇溶蛋白、谷 蛋白和谷蛋白聚合体含量及比例。

\section{5 统计分析}

利用SAS软件进行方差分析、基本统计分析、 
性状间相关性分析, 以及饼干直径的回归分析(逐步 回归法)。每个试验点次中用同一品种(系)的田间重 复籽粒样本混合, 因此方差分析中, 将试验点次作 为重复(环境), 品种(系)作为基因型。

\section{2 结果与分析}

\section{1 参试品种(系)的 HMW-GS 分析}

由表1可以看出, 参试品种(系)的HMW-GS亚基 组成及类型较简单, $G l u-A 1 、 G l u-B 1$ 和 $G l u-D 1$ 位点各 具有 2 种等位变异, 分别为 1 和null、 $7+8$ 和 $7+9 、 2+12$ 和 $5+10,3$ 个位点共 5 种组合方式。 8 份高代品系均为 宁麦 8 号、宁麦9号和扬麦9号的衍生系, 0865 和 08107 的强面筋相关亚基 $5+10$ 均来源于宁麦 8 号。

\section{2 品质性状在基因型和环境间的变异分析}

方差分析表明(附表1), 不同类型品质性状受基 因型和环境的影响不同。籽粒硬度主要由基因型决 定 $(P<0.01)$, 受环境影响较小 $(P>0.05)$ 。籽粒和面粉 蛋白含量同时受基因型和环境极显著的影响 $(P<0.01)$, 而湿面筋含量和沉淀值受基因型的影响 $(P<0.01)$ 大于受环境的影响 $(P<0.05)$ 。揉面仪特性中, 峰值时间同时受基因型和环境的显著影响 $(P<0.01)$, 8 分钟带宽主要由基因型决定 $(P<0.01)$, 其他参数在 基因型和环境间均无显著差异 $(P>0.05)$ 。4种溶剂保 持力同时受基因型 $(P<0.01)$ 和环境 $(P<0.01$ 或 $P<0.05)$ 的显著影响。粉质仪特性中, 除稳定时间受基因型 $(P<0.01)$ 和环境 $(P<0.05)$ 的共同影响外, 吸水率 $(P<0.01)$ 、形成时间 $(P<0.05)$ 和弱化度 $(P<0.01)$ 仅在 基因型间呈显著差异。面粉黏度特性中, 反弹值、 峰值时间和糊化温度仅受基因型的显著影响, 其他 参数同时受基因型和环境的显著影响 $(P<0.01$ 或 $P<0.05)$ 。基因型是可溶性谷蛋白聚合体含量、不溶 性谷蛋白聚合体含量、醇溶蛋白总量、谷蛋白/醇溶 蛋白比、不溶性谷蛋白百分比等的决定因素 $(P<0.01)$, 环境亦显著影响醇溶蛋白总量 $(P<0.05)$ 和谷蛋白/醇 溶蛋白比 $(P<0.01)$ 。谷蛋白总量在基因型和环境间均 无显著差异。饼干加工品质特性中, 饼干直径、厚 度和直径/厚度比受基因型的极显著影响 $(P<0.01)$, 饼干直径同时受环境的显著影响 $(P<0.05)$ 。

\section{3 品质性状表现}

由表2可以看出, 各类品质性状的总体变幅 $>$ 基 因型间变幅>环境间变幅。国标规定的几类品质性状 中 $^{[8-10]}$, 籽粒硬度、沉淀值和粉质仪特性参数的变异 系数较大。品种间籽粒硬度变异系数虽较大, 但均
为软质类型, 其中扬麦 9 号、扬麦 $13 、 0864 、 0865$ 、 0876、0894和08107的SKCS硬度值均低于 24, 属于 很软的类型, 仅宁麦 9 号属于中软类型, 硬度值略大 于 34 。籽粒蛋白质含量平均为 $13.6 \%$, 大于国标 $11.5 \%$ 或 $12.5 \%$ 的标准, 15 份品种(系)的平均值变幅 为 $12.9 \% \sim 14.7 \%$, 所有 45 份籽粒样本无一份达标。湿 面筋含量与蛋白质含量的表现类似，45份样本均高 于 $26 \%$, 仅宁麦 8 号、生选6号、扬麦9号和 0893 略低 于 $30 \%$ 。Z Zeleny沉淀值平均为 $26.7 \mathrm{~mL}$, 多份品种

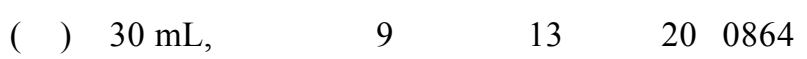
0873、0874、0876、0893和08107。粉质仪吸水率表 现较好, 基因型的平均值和不同试验点次测定值 均 $<56 \%$, 但稳定时间偏高, 基因型平均值均大于 $3 \mathrm{~min}, 0865$ 的稳定时间达到 $8.77 \mathrm{~min}$, 仅扬麦 20 和 0864 共计有 3 个试验点次的样本低于 $3 \mathrm{~min}$ 。揉面仪 测试与粉质仪测试类似，亦反映面团形成和耐揉特 性, 除峰值高度外, 峰值时间、衰落角和 $8 \mathrm{~min}$ 带宽 变幅和变异系数均较大, 能较好地区分基因型间的 差异。除乳酸溶剂保持力外, 其他 3 种溶剂保持力的 变异系数较小。醇溶蛋白总量较谷蛋白总量具有更 大的变异系数, 谷蛋白聚合体含量及比例相关参数 变异系数也相对较大。面粉秥度参数在品种间变异 系数均较小, 其中糊化时间和糊化温度的变异系数 分别仅为 $1.27 \%$ 和 $3.75 \%$ 。饼干加工方法简单, 重复 性好, 是软麦加工品质评价的常用方法。从表 2 可以 看出, 参试品种 (系) 的平均饼干直径较大, 为 $15.9 \mathrm{~cm}$, 且变异系数较小, 仅为 $1.31 \%$ 。7个品种(系) 0864、0874、0876、0893、0894、08107、宁麦8号、 扬麦 13 、扬麦 15 的饼干直径均 $\geq 16.0 \mathrm{~cm}$, 扬麦 13 和 0876 的饼干直径最大, 均为 $16.3 \mathrm{~cm}$, 其余品种(系) 饼干直径变异范围为 $15.6 \sim 15.9 \mathrm{~cm}$ 。

\section{4 品质性状与饼干加工品质的相关性分析}

从表3可以看出, 除籽粒硬度、灰分含量和面粉 黏度特性外, 其他 5 类品质性状中均有参数与饼干 加工品质显著相关。蛋白质特性中, 籽粒蛋白和沉 淀值分别与饼干直径呈显著的正向 $(P<0.05)$ 和负向 相关性 $(P<0.01)$ 。粉质仪特性中, 吸水率和稳定时间 均与饼干直径呈显著负相关 $(P<0.05)$, 吸水率亦与 饼干直径/厚度比呈显著负相关 $(P<0.05)$ 。揉面仪特 性中, 峰值时间与饼干直径呈极显著负相关 $(P<0.01)$, 衰落角与饼干3个品质指标均呈极显著相 关 $(P<0.01)$, 衰减越快则饼干直径越大。蔗糖溶剂保 持力与饼干加工品质无显著相关性, 而水、碳酸钠 
表 2 品质性状的平均值及变幅

Table 2 Mean and range of quality trait parameters

\begin{tabular}{|c|c|c|c|c|c|}
\hline $\begin{array}{c}\text { 品质性状参数 } \\
\text { Quality trait parameter }\end{array}$ & $\begin{array}{c}\text { 总体平均值 } \\
\text { Overall mean } \\
(N=45)\end{array}$ & $\begin{array}{c}\text { 总体变幅 } \\
\text { Overall range } \\
(N=45) \\
\end{array}$ & $\begin{array}{c}\text { 基因型变幅 } \\
\text { Genotypic range } \\
(N=15) \\
\end{array}$ & $\begin{array}{c}\text { 环境变幅 } \\
\text { Environmental } \\
\text { range }(N=3) \\
\end{array}$ & $\begin{array}{c}\text { 变异系数 } \\
\mathrm{CV}(\%) \\
(N=15)\end{array}$ \\
\hline \multicolumn{6}{|l|}{ 磨粉品质 Milling quality } \\
\hline 籽粒硬度 Kernel hardness & 25.5 & 12.4 to 36.5 & 14.6 to 35.0 & 25.2 to 25.7 & 23.93 \\
\hline 灰分 Ash (\%) & 0.51 & 0.44 to 1.46 & 0.46 to 0.79 & 0.47 to 0.57 & 15.74 \\
\hline \multicolumn{6}{|l|}{ 蛋白质特性 Protein traits } \\
\hline 籽粒蛋白 Kernel protein (\%) & 13.6 & 12.6 to 14.7 & 12.9 to 14.3 & 13.6 to 13.7 & 3.03 \\
\hline 面粉蛋白 Flour protein (\%) & 11.0 & 9.7 to 12.7 & 10.2 to 11.8 & 10.9 to 11.1 & 4.36 \\
\hline 湿面筋含量 Wet gluten (\%) & 31.0 & 28.4 to 35.3 & 29.1 to 32.9 & 30.8 to 31.2 & 4.01 \\
\hline Zeleny 沉淀值 Sedimentation (mL) & 26.7 & 18.4 to 38.6 & 18.9 to 36.9 & 26.1 to 27.3 & 25.09 \\
\hline \multicolumn{6}{|l|}{ 粉质仪特性 Farinograph } \\
\hline 吸水率 Absorption (\%) & 53.0 & 51.8 to 55.8 & 52.0 to 54.7 & 52.9 to 53.2 & 1.48 \\
\hline 形成时间 Development time (min) & 2.2 & 1.3 to 4.8 & 1.3 to 3.3 & 2.0 to 2.3 & 26.70 \\
\hline 稳定时间 Stability (min) & 4.8 & 2.6 to 10.5 & 3.1 to 8.8 & 4.3 to 5.2 & 31.66 \\
\hline 弱化度 Weakness (BU) & 90.6 & 49.0 to 128.0 & 54.7 to 124.3 & 88.8 to 93.1 & 19.63 \\
\hline \multicolumn{6}{|l|}{ 揉面仪特性 Mxiograph } \\
\hline 峰值时间 Peak time (min) & 2.0 & 1.1 to 3.0 & 1.3 to 2.7 & 1.9 to 2.2 & 19.84 \\
\hline 峰值高度 Peak value (\%) & 46.8 & 42.8 to 62.3 & 43.9 to 51.1 & 46.1 to 47.6 & 3.71 \\
\hline 衰落角 Right of peak slope $\left(\% \mathrm{~min}^{-1}\right)$ & -1.4 & -4.0 to -0.1 & -2.4 to -0.7 & -1.5 to -1.3 & 33.41 \\
\hline 8 分钟带宽 TimeX (\%) & 4.9 & 2.8 to 7.5 & 3.9 to 6.8 & 4.7 to 5.2 & 16.56 \\
\hline \multicolumn{6}{|l|}{ 溶剂保持力 Solvent retention capacity } \\
\hline 水溶剂保持力 Water SRC (\%) & 58.2 & 54.1 to 62.8 & 55.6 to 60.9 & 57.4 to 59.2 & 2.41 \\
\hline 碳酸钠溶剂保持力 Sodium carbonate SRC (\%) & 74.7 & 69.2 to 85.8 & 70.7 to 81.15 & 73.0 to 76.7 & 4.23 \\
\hline 蔗糖溶剂保持力 Sucrose SRC (\%) & 107.5 & 100.3 to 124.8 & 102.1 to 118.4 & 106.2 to 108.8 & 4.35 \\
\hline 乳酸溶剂保持力 Lactic acid SRC (\%) & 102.8 & 83.3 to 124.7 & 87.6 to 123.7 & 100.5 to 104.6 & 9.49 \\
\hline \multicolumn{6}{|l|}{ 贮藏蛋白组分 Gluten protein fractions } \\
\hline 可溶性谷蛋白聚合体 EPP $\left(A U \mathrm{mg}^{-1}\right)$ & 262.6 & 202.6 to 328.2 & 226.9 to 303.4 & 260.5 to 264.9 & 8.29 \\
\hline 不溶性谷蛋白聚合体 UPP (AU mg ${ }^{-1}$ ) & 182.5 & 147.6 to 222.6 & 159.5 to 205.8 & 178.4 to 189.2 & 7.27 \\
\hline 不溶性谷蛋白聚合体百分含量 \%UPP & 41.1 & 33.5 to 48.4 & 35.7 to 46.9 & 40.3 to 42.0 & 7.80 \\
\hline 谷蛋白总量 Total glutenin protein (AU mg $\left.{ }^{-1}\right)$ & 445.3 & 370.0 to 528.5 & 423.3 to 489.5 & 442.3 to 450.3 & 4.37 \\
\hline 醇蛋白总量 Total gliadin protein (AU mg $\left.{ }^{-1}\right)$ & 319.7 & 236.1 to 408.0 & 260.5 to 362.2 & 318.5 to 321.0 & 8.67 \\
\hline 谷蛋白/醇溶蛋白 Glutenin/gliadin & 1.4 & 1.2 to 1.8 & 1.3 to 1.7 & 1.39 to 1.41 & 6.63 \\
\hline \multicolumn{6}{|l|}{ 黏度仪参数 Rapid viscocity analysis } \\
\hline 峰值黏度 Peak viscocity (RVU) & 3136.3 & 2479.0 to 3594.0 & 2835.7 to 3357.8 & 3046.0 to 3196.6 & 4.56 \\
\hline 低谷黏度 Through viscocity (RVU) & 1865.4 & 143.1 to 2260.5 & 1669.1 to 2102.1 & 1799.9 to 1903.7 & 5.78 \\
\hline 稀懈值 Break down (RVU) & 1270.9 & 1043.0 to 1449.0 & 1166.5 to 1410.8 & 1246.2 to 1292.8 & 5.43 \\
\hline 最终黏度 Final viscocity (RVU) & 3328.0 & 2727.0 to 3990.0 & 3077.3 to 3743.5 & 3234.5 to 3383.5 & 5.12 \\
\hline 反弹值 Set back (RVU) & 1462.6 & 1145.5 to 1729.5 & 1253.0 to 1641.3 & 1434.6 to 1479.8 & 6.37 \\
\hline 峰值时间 Peak time (min) & 6.2 & 5.9 to 6.4 & 6.0 to 6.3 & 6.1 to 6.2 & 1.27 \\
\hline 糊化温度 Pasting temperature $\left({ }^{\circ} \mathrm{C}\right)$ & 81.8 & 71.0 to 86.4 & 74.1 to 85.3 & 80.5 to 82.7 & 3.75 \\
\hline \multicolumn{6}{|l|}{ 酥性饼干品质 Sugar snap cookie } \\
\hline 饼干直径 Cookie diameter (cm) & 15.9 & 15.3 to 16.5 & 15.6 to 16.3 & 15.9 to 16.1 & 1.31 \\
\hline 饼干厚度 Cookie thickness (cm) & 3.3 & 2.6 to 3.9 & 2.8 to 3.6 & 3.2 to 3.4 & 7.86 \\
\hline 直径/厚度 Diameter/thickness & 4.9 & 4.0 to 6.3 & 4.3 to 5.9 & 4.9 to 5.2 & 9.58 \\
\hline
\end{tabular}

SRC: solvent retention capacity; EPP: extractable polymeric protein; UPP: unextractable polymeric protein.

和乳酸溶剂保持力与饼干直径皆呈极显著负相关 $(P<0.01)$ ，相关系数分别为 $-0.857 、-0.726$ 和 -0.616 。
谷蛋白/醇溶蛋白比、不溶性谷蛋白聚合体含量与饼 干直径呈显著负相关 $(P<0.05)$ 。 
表 3 品质性状与饼干加工品质的相关系数

Table 3 Correlation coefficients between cookie making quality and quality trait parameters

\begin{tabular}{|c|c|c|c|}
\hline $\begin{array}{c}\text { 品质性状 } \\
\text { Quality trait }\end{array}$ & $\begin{array}{c}\text { 饼干直径 } \\
\text { Cookie diameter }\end{array}$ & $\begin{array}{c}\text { 饼干厚度 } \\
\text { Cookie thickness }\end{array}$ & $\begin{array}{c}\text { 饼干直径/厚度 } \\
\text { Diameter/thickness }\end{array}$ \\
\hline 籽粒硬度 Kernel hardness & -0.155 & 0.271 & -0.268 \\
\hline 灰分 Ash & 0.239 & -0.364 & 0.372 \\
\hline 籽粒蛋白 Kernel protein & $0.523^{*}$ & -0.484 & 0.461 \\
\hline 面粉蛋白 Flour protein & 0.398 & -0.224 & 0.224 \\
\hline 湿面筋 Wet gluten & 0.415 & -0.300 & 0.293 \\
\hline 沉淀值 Sedimentation & $-0.657^{* *}$ & 0.420 & -0.462 \\
\hline 吸水率 Absorption & $-0.601^{*}$ & 0.510 & $-0.520^{*}$ \\
\hline 形成时间 Development time & 0.200 & -0.024 & 0.039 \\
\hline 稳定时间 Stability & $-0.617^{*}$ & 0.306 & -0.367 \\
\hline 弱化度 Weakness & 0.443 & -0.174 & 0.237 \\
\hline 峰值时间 Peak time & $-0.659^{* *}$ & 0.438 & -0.467 \\
\hline 峰值高度 Peak value & 0.157 & -0.236 & 0.233 \\
\hline 衰落角 Right of peak slope & $-0.676^{* *}$ & $0.659^{* *}$ & $-0.697^{* *}$ \\
\hline 8 分钟带宽 TimeX & -0.377 & 0.144 & -0.220 \\
\hline 水溶剂保持力 Water SRC & $-0.857^{* * *}$ & $0.682^{*}$ & $-0.720^{* *}$ \\
\hline 碳酸钠溶剂保持力 Sodium carbonate SRC & $-0.726^{* *}$ & $0.520^{*}$ & $-0.543^{*}$ \\
\hline 蔗糖溶剂保持力 Sucrose SRC & -0.447 & 0.345 & -0.368 \\
\hline 乳酸溶剂保持力 Lactic acid SRC & $-0.616^{*}$ & 0.357 & -0.394 \\
\hline 可溶性谷蛋白聚合体 EPP & 0.511 & -0.314 & 0.308 \\
\hline 不溶性谷蛋白聚合体 UPP & $-0.541^{*}$ & 0.293 & -0.322 \\
\hline 不溶性谷蛋白聚合体百分含量 \%UPP & $-0.637^{*}$ & 0.395 & -0.404 \\
\hline 谷蛋白总量 Total glutenin protein & 0.215 & -0.171 & 0.144 \\
\hline 醇蛋白总量 Total gliadin protein & 0.493 & -0.265 & 0.265 \\
\hline 谷蛋白/醇溶蛋白 Glutenin/gliadin & $-0.546^{*}$ & 0.266 & -0.279 \\
\hline 峰值黏度 Peak viscocity & 0.106 & -0.315 & 0.262 \\
\hline 低谷黏度 Through viscocity & -0.019 & -0.119 & 0.061 \\
\hline 稀解值 Break down & 0.249 & -0.466 & 0.448 \\
\hline 最终黏度 Final viscocity & -0.253 & 0.100 & -0.152 \\
\hline 反弹值 Set back & -0.442 & 0.322 & -0.348 \\
\hline 峰值时间 Peak time & 0.199 & -0.132 & 0.116 \\
\hline 糊化温度 Pasting temperature & -0.361 & 0.169 & -0.204 \\
\hline
\end{tabular}

${ }^{*}$ 、 ${ }^{* *}$ 和 ${ }^{* * *}$ 分别表示相关性显著水平为 $0.05 、 0.01$ 和 0.001 。

${ }^{*},{ }^{* *}$, and ${ }^{* * *}$ indicated the significance at the $0.05,0.01$, and 0.001 probability levels, respectively. SRC: solvent retention capacity; EPP: extractable polymeric protein; UPP: unextractable polymeric protein.

\section{5 品质性状间的相关性分析}

国标涉及的品质参数 ${ }^{[8-10]}$, 以及与饼干加工品 质显著相关的品质参数(表4)进行相关性分析(表 5), 可以看出, 籽粒蛋白、粉质仪吸水率与其他品质参 数的相关性较弱, 籽粒蛋白仅与揉面仪峰值时间 $(P<0.05)$ 、不溶性谷蛋白聚合体百分含量和谷蛋白/
醇溶蛋白比呈显著相关 $(P<0.01)$, 吸水率仅与水溶 剂保持力呈显著相关 $(P<0.05)$ 。除籽粒蛋白和粉质 仪吸水率外, 其他各类品质参数间及参数内高度相 关, 如沉淀值与乳酸溶剂保持力极显著正相关, 相 关系数为 $0.924(P<0.001)$, 两者皆与其他各类品质 参数密切相关, 其中与粉质仪稳定时间、揉面仪峰 







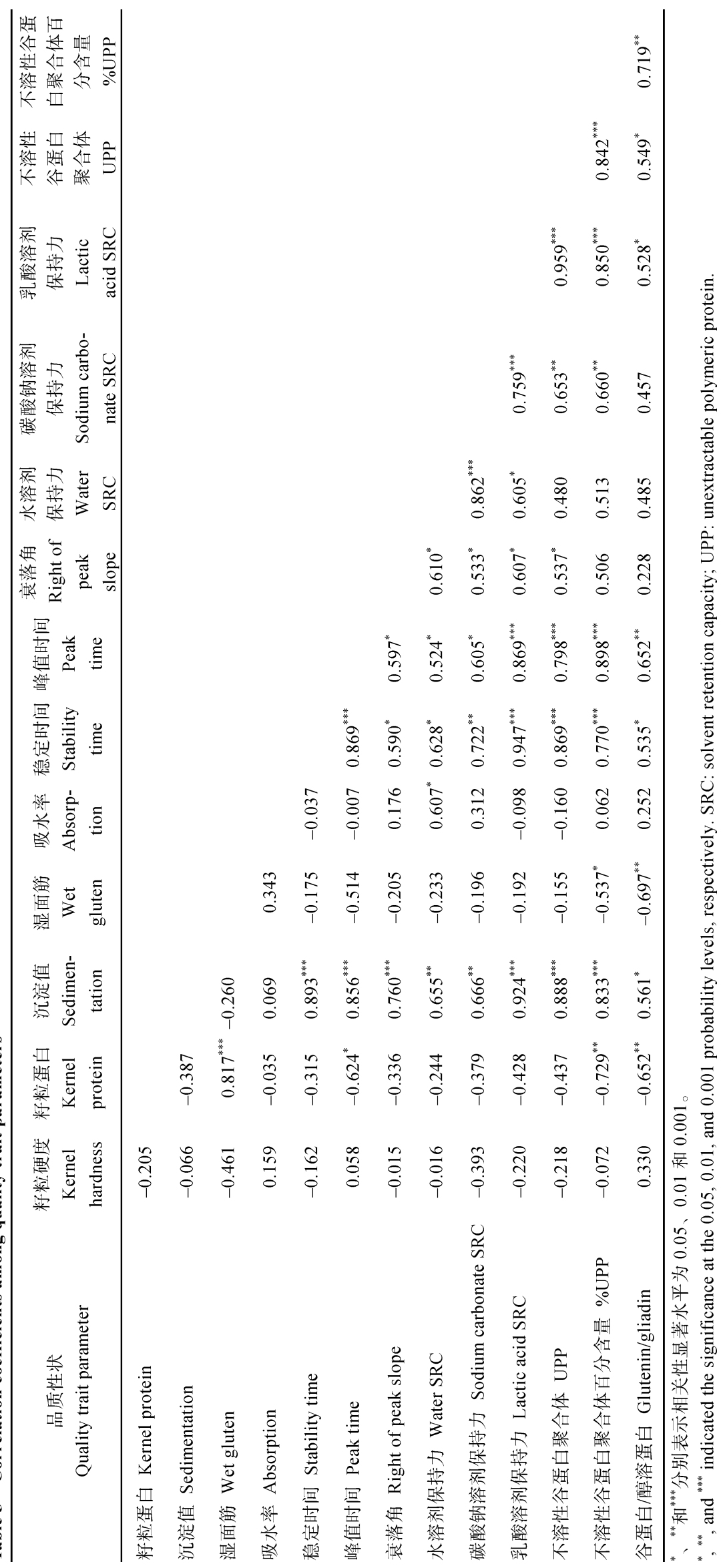


值时间、不溶性谷蛋白聚合体及百分含量的相关系 数均大于 $0.800(P<0.001)$ 。水、碳酸钠和乳酸溶剂 保持力之间呈显著相关。除籽粒硬度、籽粒蛋白、 湿面筋含量和部分谷蛋白组分定量参数外, 水和碳 酸钠溶剂保持力亦与其他各类品质参数均呈显著 相关。揉面仪峰值时间与粉质仪稳定时间均反映面 团强度, 两者呈高度正相关, 相关系数为 0.869 $(P<0.001)$ 。

\section{6 品质性状与饼干直径的回归分析}

以饼干直径 $(\mathrm{cm})$ 为应变量 $Y, 12$ 个显著影响饼干 加工品质的品质性状(表4)为自变量 $X$, 进行线性回 归分析, 获得 2 个达显著水平的回归模型。模型I为 $Y=$ 23.4592-0.1291 $X_{1}$, 其中 $X_{1}$ 为水溶剂保持力, 模型、

常数、 $X_{1}$ 的 $F$ 值分别为 $36.55 \quad(P<0.001) 、 356.36$ $(P<0.001) 、 36.55(P<0.001)$, 该模型利用水溶剂保持 力可解释饼干直径变异的 $73.76 \%$ 。模型 II 为 $Y=$ $20.4647-0.1169 X_{1}+0.1676 X_{2}$, 其中 $X_{1}$ 为水溶剂保持 力, $X_{2}$ 为籽粒蛋白, 模型、常数、 $X_{1} 、 X_{2}$ 的 $F$ 值分别为 $31.27(P<0.001) 、 189.23(P<0.001) 、 42.33(P<0.001) 、$ $7.56(P<0.05)$, 该模型利用水溶剂保持力和籽粒蛋 白共同可解释饼干直径变异的 $83.90 \%$ 。

\section{3 讨论}

\section{1 软麦品种(系)品质状况}

从小麦品种品质分类标准看, GB/T 17320$2013^{[8]}$ 与旧标准 GB/T 17320-1998 ${ }^{[9]}$ 相比, 不再限定 软质小麦品种的拉伸仪参数指标, 但将蛋白质含量 和湿面筋含量由旧标准的 $<13.0 \%$ 和 $<28.0 \%$ 降低为 新标准的 $<12.5 \%$ 和 $<26 \%$, 同时要求籽粒硬度应小 于50。从商品小麦流通领域看, GB/T 17893-1999 ${ }^{[10]}$ 以满足加工适用性为目标, 限定蛋白质含量、湿面筋 含量和粉质仪稳定时间分别为 $\leq 11.5 \%$ 、 $\leq 22.0 \%$ 和 $\leq$ $2.5 \mathrm{~min}$ 。对照这些标准, 在本研究条件下, 仅籽粒硬 度和吸水率达标, 以及部分样本的沉淀值达标, 表 明当前软麦生产蛋白质含量和面筋强度仍是主要限 制因子。我们前期研究表明, 在低氮条件下(纯氮 $120 \mathrm{~kg} \mathrm{hm}^{-2}$ ), 本文中 6 个软麦品种均可生产蛋白质 含量达标(GB/T 17893-1999)的优质小麦 ${ }^{[7]}$, 现有的 氮肥管理措施难以生产达标优质小麦 ${ }^{[20]}$ 。陆增根等 ${ }^{[21]}$ 对宁麦9号和扬麦9号的研究表明, 实现 $7000 \mathrm{~kg} \mathrm{hm}^{-2}$ 的优质生产, 纯氮施用量需减至 $200 \mathrm{~kg} \mathrm{hm}^{-2}$, 并配 合氮肥前移策略。吴宏亚等 ${ }^{[6]}$ 和王曙光等 ${ }^{[22]}$ 则表明, $210 \mathrm{~kg} \mathrm{hm}^{-2}$ 和 $225 \mathrm{~kg} \mathrm{hm}^{-2}$ 施氮水平下, 扬麦 15 和宁
麦9号可分别在江苏扬州地区和太湖地区实现优质 高产。这不仅与扬麦 15 和宁麦 9 号不同的氮肥敏感性 有关 ${ }^{[7]}$, 也与蛋白质含量对环境条件的敏感性有关, 如本研究所有与蛋白含量相关的品质参数均受到环 境的显著影响。因此, 大面积软麦优质高产需要以 减氮为基础, 发挥品种、区域生态和肥料管理的综


议以 $\geq 16 \mathrm{~cm}$ (2块饼干直径之和)作为优质软麦样本 的标准, 本研究在蛋白质含量超标的情况下, 仍有 多份品种(系)达到加工优质饼干的标准, 其中扬麦 13 和0876表现突出。这表明蛋白质含量、湿面筋含 量等反映蛋白质数量的指标与加工品质间没有必然 的联系, 相关标准可以适当放宽或者增加终端产品 加工品质作为参考。

\section{2 软麦品种品质特性与加工品质的关系}

本研究籽粒蛋白、面粉蛋白、湿面筋含量与饼 干直径呈弱相关或无显著关联, 而面筋强度相关指 标均与饼干加工品质呈显著负相关，表明在较高蛋 白质含量水平下，通过降低面筋强度，如粉质仪稳 定时间、揉面仪峰值时间等，可显著提高饼干的加 工品质。一般认为, 优化HMW-GS组成对提高中强 筋和强筋小麦加工品质效果显著 ${ }^{[23]}$, 而对蛋白质含 量较低的软质小麦加工品质影响较小 ${ }^{[24]}$ 。但最近的 研究表明, HMW-GS对软麦面筋质量和加工品质也 具有重要的作用，如美东软麦中的Glu-B1 $(13+16)$ 、 Glu-B1 $\left(7^{\mathrm{OE}}+8\right)$ 和 Glu-D1 $(5+10)$ 可显著提高软麦的面 筋强度 ${ }^{[14]}$, 阿根廷中部软麦饼干加工品质的最优组 合为 Glu-A1(null)/Glu-B1(7+8)/Glu-D1(2+12)。本研 究中亚基组成与面筋强度无明显关联，宁麦 8 号、 0865和08107均具有Glu-D1(5+10)强面筋亚基, 但面 筋强度品质指标和饼干直径在 3 个品种(系)间差异较 大，其余相同亚基组成的品种(系)也具有类似的表 现。咜藏蛋白组分含量特征、溶剂保持力等性状与 饼干直径的显著相关性进一步表明, 除HMW-GS外 多种因素对饼干加工品质均有重要影响。从15份参 试材料的系谱看，除扬麦13和扬麦 15 外，均为扬麦 5 号、扬麦 6 号和扬麦 9 号的衍生系, 可见当前该麦区 软麦育种的遗传基础狭窄, 制约了品质的进一步提 高，急需创制和引入新的种质资源。最近报道通过 HMW-GS缺失可能是改善面筋强度、提高软麦加工 品质的途径之一。张平平等 ${ }^{[25]}$ 和Zhang等 ${ }^{[26]}$ 分别利 用单个HMW-GS或 $G l u-1$ 位点缺失可显著降低面团 弹性, 提高饼干加工品质。Zhang等 ${ }^{[27]}$ 和 Tuncil等 ${ }^{[28]}$ 
利用特定HMW-GS组成的个别亚基缺失可同时改善 面团弹性和延展性。结合HMW-GS组成和亚基缺失 可能是提高软麦加工品质的途径之一。

\section{3 软麦加工品质预测指标的利用}

本研究试验材料蛋白含量差异较小, 所有样本 的籽粒硬度均达标, 两者都与其他类型的品质性状 和饼干加工品质均无显著关联, 与前期对软麦育种 群体的研究结果一致 ${ }^{[3]}$, 表明蛋白质含量和硬度只 是优质软麦的必要条件, 仅可作为育种材料最基本 的分类篮选标准。揉面仪测试以往多在中强筋小麦 育种应用 ${ }^{[29-30]}$, 本研究中的揉面仪参数在基因型间 变异系数大, 峰值时间与粉质仪稳定时间、Zeleny 沉淀值, 以及饼干直径均呈极显著正相关, 表明其 在软麦选育中亦具有实用性。除熫糖溶剂保持力外, 其他 3 种溶剂保持力均与饼干加工品质显著相关, 这与国内外学者研究结果基本一致 ${ }^{[11,16,31-32]}$ 。本研究 中水溶剂保持力对饼干直径具有很好的预测效果, 利用其建立的回归方程可解释饼干直径变异的 $73.76 \%$, 配合籽粒蛋白共同可解释饼干直径变异的 $83.90 \%$, 而Zhang 等 ${ }^{[16]}$ 的饼干直径预测模型, 突出 了蔗糖溶剂保持力的重要性, 这与试验材料有关, 本研究中蔗糖溶剂保持力与饼干加工无显著相关 性。另外, 本研究显示沉淀值和乳酸溶剂保持力高 度正相关, 均与面筋强度和饼干直径密切相关, 与 前人研究结果基本一致 ${ }^{[33-34]}$ 。乳酸溶剂保持力与面 筋特性关联, 较沉淀值测定方法简单、通量高, 对测 试环境、试剂要求较低, 稳定性好, 可作为面筋强度 选择的重要方法。因此, 在软麦育种群体 $\mathrm{F}_{2} \sim \mathrm{F}_{3}$ 代可 利用近红外方法对硬度和籽粒蛋白初步䇻选, $\mathrm{F}_{4}$ 增 加水和乳酸溶剂保持力对综合吸水特性和面筋质量 的篮选, $F_{5} \sim \mathrm{F}_{6}$ 增加揉面仪测定面团揉混特性, 对产 量圃中选品系可进行粉质仪测试和微量饼干加工测 试。

\section{4 结论}

江苏淮南麦区软麦品种(系)在一般大田管理条 件下, 仅籽粒硬度和粉质仪吸水率符合国标要求, 蛋白质含量和面筋强度相关指标较难符合国标规 定。籽粒硬度、面筋强度和溶剂保持力等品质性状 仍有较大改良空间。在籽粒硬度和蛋白含量选择的 基础上, 降低面筋强度和面粉综合吸水特性是软麦 育种的主要目标, 水溶剂保持力、乳酸溶剂保持力 和揉面仪参数是重要的篮选指标。

\section{References}

[1] 张岐军, 张艳, 何中虎, Peña R J. 软质小麦品质性状与酥性饼 干品质参数的关系研究. 作物学报, 2005, 31: 1125-1131.

Zhang Q J, Zhang Y, He Z H, Peña R J. Relationship between soft wheat quality traits and cookie quality parameters. Acta Agron Sin, 2005, 31: 1125-1131 (in Chinese with English abstract).

[2] 姚金保, Souza E, 马鸿翔, 张平平, 姚国才, 杨学明, 任丽娟, 张鹏. 软红冬小麦品质性状与饼干直径的关系. 作物学报, 2010, 36: 695-700.

Yao J B, Souza E, Ma H X, Zhang P P, Yao G C, Yang X M, Ren L J, Zhang P. Relationship between quality traits of soft red winter wheat and cookie diameter. Acta Agron Sin, 2010, 36: 695-700 (in Chinese with English abstract).

[3] 张平平, 姚金保, 马鸿翔, 杨学明, 张鹏, 姚国才, 张旭, 杨丹. 宁麦 9 号衍生系及酥性饼干直径的关系. 麦类作物学报, 2013, 33: 1156-1161.

Zhang P P, Yao J B, Ma H X, Yang X M, Zhang P, Yao G C, Zhang X, Yang D. Quality traits of Ningmai 9 and its derivate lines and their relationship with cookie diameter. $J$ Triticeae Crops, 2013, 33: 1156-1161 (in Chinese with English abstract).

[4] 中华人民共和国农业部种植业管理司. 2014 中国小麦质量报 告. 北京, 2014. pp 69-83.

Department of Planting Management, Ministry of Agriculture of the People's Republic of China. 2014 Wheat Quality Report in China. Beijing, 2014. pp 69-83 (in Chinese).

[5] 中华人民共和国农业部种植业管理司. 2015 中国小麦质量报 告. 北京, 2015. pp 70-85.

Department of Planting Management, Ministry of Agriculture of the People's Republic of China. 2014 Wheat Quality Report in China. Beijing, 2015. pp 70-85 (in Chinese).

[6] 吴宏亚, 汪尊杰, 张伯桥, 程顺和. 氮肥追施比例对弱筋小麦 扬麦 15 籽粒产量及品质的影响. 麦类作物学报, 2015, 35: 258-262.

Wu H Y, Wang Z J, Zhang B Q, Cheng S H. Effect of nitrogen application ratio on grain yield and quality of weak gluten wheat cultivar Yangmai 15. J Triticeae Crops, 2015, 35: 258-262 (in Chinese with English abstract).

[7] 王化敦, 史高玲, 张平平, 张鹏, 高春蕾, 姚金保, 马鸿翔. 长 江中下游小麦品种籽粒品质对氮素的敏感性分析. 南方农业 学报, 2017,48: 1568-1573.

Wang H D, Shi G L, Zhang P P, Zhang P, Gao C L, Yao J B, Ma $\mathrm{H}$ X. Sensitivity of wheat grain quality to nitrogen application in middle and lower reaches of Yangtze River. J Southern Agric, 2017, 48: 1568-1573 (in Chinese with English abstract).

[8] 中华人民共和国国家质量监督检验检疫总局/中国国家标准化 管理委员会. GB/T 17320-2013 小麦品种品质分类. 北京: 中 国标准出版社. 2013.

General Administration of Quality Supervision, Inspection and Quarantine of PRC/China National Standardization Management Committee. GB/T 17320-2013 Quality Classification of Wheat Varieties. Beijing: Standards Press of China. 2013.

[9] 中华人民共和国国家质量监督检验检疫总局/中国国家标准化 管理委员会. GB/T 17320-1998 小麦品种品质分类. 北京: 中 国标准出版社. 1998.

General Administration of Quality Supervision, Inspection and 
Quarantine of PRC/China National Standardization Management Committee. GB/T 17320-1998 Quality Classification of Wheat Varieties. Beijing: Standards Press of China, 1998.

[10］国家质量技术监督局. GB/T 17893-1999 优质小麦 弱筋小麦. 北京: 中国标准出版社, 1999.

The Quality and Technology Supervision Bureau. GB/T 17893-1999 High Quality Wheat-Weak gluten wheat. Beijing: Standards Press of China. 1999.

[11] Geng Z M, Zhang P P, Yao J B, Yang D, Ma H X, Rayas-Duarte P. Physicochemical and rheological properties of Chinese soft wheat flours and their relationship with cookie-making quality. Cereal Chem, 2012, 89: 237-241

[12] 李硕碧, 裴阿卫, 李必运. 小麦品质性状的遗传及选择方法研 究. 作物学报, 2002, 28: 816-820.

Li S B, Pei A W, Li B Y. Study on inheritance and selection method of wheat qualities. Acta Agron Sin, 2002, 28: 816-820 (in Chinese with English abstract).

[13] 韩玉林, 邓志英, 郑天存, 陈广凤, 田纪春. 相同 HMW-GS 组 合小麦品种的主要品质指标分析. 麦类作物学报, 2008, 28: $51-55$.

Han Y L, Deng Z Y, Zheng T C, Chen G F, Tian J C. Analysis on main quality index of wheat cultivars with the same HMW-GS combination. J Triticeae Crops, 2008, 28: 51-55 (in Chinese with English abstract).

[14] Ma F Y, Kim J, Cho E, Brown-Guedira G, Park C S, Baik B K. HMW-GS composition and rye translocations of U.S. eastern soft winter wheat and their associations with protein strength. $J$ Cereal Sci, 2019, https://doi.org/10.1016/j.jcs.2019.102799.

[15] 张伯桥, 张晓, 高德荣, 吕国锋, 朱冬梅, 马谈斌. 吹泡仪参 数作为弱筋小麦品质育种选择指标的评价. 麦类作物学报, 2010, 30: 29-33.

Zhang B Q, Zhang X, Gao D R, Lyu G F, Zhu D M, Ma T B. The value of alveograph parameters used as selection index in weak gluten wheat breeding. J Triticeae Crops, 2010, 30: 29-33 (in Chinese with English abstract).

[16] Zhang Q J, Zhang Y, Zhang Y, He Z H, Peña R J. Effects of solvent retention capacities, pentosan content, and dough rheological properties on sugar snap cookie quality in Chinese soft wheat genotypes. Crop Sci, 2007, 47: 656-664.

[17] AACC International. Approved Methods of Analysis (11th edn). AACCI, St Paul, MN. 2002

[18] Liu L, He Z H, Yan J, Zhang Y, Xia X C, Peña R J. Allelic variation at the Glu-1 and Glu-3 loci, presence of 1B·1R translocation, and their effects on mixographic properties in Chinese bread wheats. Euphytica, 2005, 142: 197-204.

[19] Larroque O R, Gianibelli M C, Gomez Sanchez M, MacRitchie F. Procedure for obtaining stable protein extracts of cereal flour and whole meal for size-exclusion HPLC analysis. Cereal Chem, 2000, 77: 448-450.

[20] 张平平, 刘婷婷, 姚金保, 马鸿翔, 张鹏, 杨学明, 周沝平. 栽 培措施对软红冬小麦加工品质的效应. 麦类作物学报, 2016, 36: 789-794.

Zhang P P, Liu T T, Yao J B, Ma H X, Zhang P, Yang X M, Zhou M P. Effect of cultivation strategies on processing quality of soft red winter wheat. J Triticeae Crops, 2016, 36: 789-794 (in Chinese with English abstract).
[21] 陆增根, 戴廷波, 姜东, 荆奇, 吴正贵, 周培南, 曹卫星. 氮肥 运筹对弱筋小麦群体指标与产量和品质形成的影响. 作物学 报, 2007, 33: 590-597.

Lu Z G, Dai T B, Jiang D, Jing Q, Wu Z G, Zhou P N, Cao W X. Effects of nitrogen strategies on population quality index and grain yield and quality in weak-gluten wheat. Acta Agron Sin, 2007, 33: 590-597 (in Chinese with English abstract).

[22] 王曙光, 许轲, 戴其根, 张洪程, 霍中洋, 黄萍霞. 氮肥运筹 对太湖麦区弱筋小麦宁麦 9 号产量与品质的影响. 麦类作物 学报, 2005, 25: 65-68.

Wang S G, Xu K, Dai Q G, Zhang H C, Huo Z Y, Huang P X. Effect of nitrogen applying methods on yield and quality of Ningmai 9 in Taihu region. $J$ Triticeae Crops, 2005, 25: 65-68 (in Chinese with English abstract).

[23] 张勇, 申小勇, 张文祥, 陈新民, 阎俊, 张艳, 王德森, 王忠伟, 刘悦芳, 田宇兵, 夏先春, 何中虎. 高分子量谷蛋白 $5+10$ 亚基 和 $1 \mathrm{~B} / 1 \mathrm{R}$ 易位分子标记辅助选择在小麦品质育种中的应用. 作物学报, 2012, 38: 1743-1751.

Zhang Y, Sheng X Y, Zhang W X, Chen X M, Yan J, Zhang Y, Wang D S, Wang Z W, Liu Y F, Tian Y B, Xia X C. Marker-assisted selection of HMW-glutenin $1 D x 5+1 D y 10$ gene and $1 \mathrm{~B} / 1 \mathrm{R}$ translocation for improving industry quality in common wheat. Acta Agron Sin, 2012, 38: 1743-1751 (in Chinese with English abstract).

[24] Moiraghi M, Vanzetti L, Pflüger L, Helguera M, Pérez G T. Effect of high molecular weight glutenins and rye translocations on soft wheat flour cookie quality. J Cereal Sci, 2013, 58: 424-430.

[25] 张平平, 马鸿翔, 姚金保, 周永平, 张鹏. 高分子量谷蛋白单 亚基缺失对软质小麦宁麦 9 号加工品质的影响. 作物学报, 2016, 42: 633-640.

Zhang P P, Ma H X, Yao J B, Zhou M P, Zhang P. Effect of HMW-GS deletion on processing quality of soft wheat Ningmai 9. Acta Agron Sin, 2016, 42: 633-640 (in Chinese with English abstract).

[26] Zhang X, Zhang B Q, Wu H Y, Lu C B, Lü G F, Li D T, Li M, Jiang W, Song G H, Gao D R. Effect of high-molecular-weight glutenin subunit deletion on soft wheat quality properties and sugar-snap cookie quality estimated through near-isogenic lines. $J$ Integr Agric, 2018, 17: 1066-1073.

[27] Zhang P P, Jondiko T O, Tilley M, Awika J M. Effect of high molecular weight glutenin subunit composition in common wheat on dough properties and steamed bread quality. J Sci Food Agric, 2014, 94: 2801-2806.

[28] Tuncil Y E, Jondiko T, Tilley M, Hays D B, Awika J M. Combination of null alleles with 7+9 allelic pair at Glu-B1 locus on the long arm of group 1 chromosome improves wheat dough functionality for tortillas. LWT: Food Sci Tech, 2016, 65: 683-688.

[29] 申小勇, 阎俊, 陈新民, 张艳, 李慧玲, 王德森, 何中虎, 张勇. 和面仪参数与粉质仪、拉伸仪及面包成品加工品质主要参数 的关系. 作物学报, 2010, 36: 1037-1043.

Shen X Y, Yan J, Chen X M, Zhang Y, Li H L, Wang D S, He Z H, Zhang Y. Relationship of mixograph parameters with farinograph and extensograph parameters, and bread-making quality traits. Acta Agron Sin, 2010, 36: 1037-1043 (in Chinese with English abstract).

[30] 张勇, 张立平, 阎俊, 张艳, 王德森, 刘建军, 何中虎. 普通小 
麦面筋强度早代选择研究. 作物学报, 2006, 32: 1663-1670.

Zhang Y, Zhang L P, Yan J, Wang D S, Liu J J, He Z H. Early generation selection of gluten strength in common wheat. Acta Agron Sin, 2006, 32: 1663-1670 (in Chinese with English abstract).

[31] Guttieri M J, Souza E. Sources of variation in the solvent retention capacity test of wheat flour. Crop Sci, 2003, 43: 1628-1633.

[32] Ram S, Singh R P. Solvent retention capacities of Indian wheats and their relationship with biscuit making quality. Cereal Chem,
2004, 81: 128-133.

[33] Ram S, Dawar V, Singh R P, Shoran J. Application of solvent retention capacity tests for the prediction of mixing properties of wheat flour. J Cereal Sci, 2005, 42: 261-266.

[34] Xiao Z S, Park S H, Chung O K, Caley M S, Seib P A. Solvent retention capacity values in relation to hard winter wheat and flour properties and straight-dough bread making quality. Cereal Chem, 2006, 83: 465-471.

附表 1 䊏粒硬度、灰分含量和蛋白质特性相关性状方差分析(均方值)

Supplementary table 1 Analysis of variation of quality trait parameters (mean square)

\begin{tabular}{|c|c|c|c|}
\hline $\begin{array}{c}\text { 品质性状参数 } \\
\text { Quality trait parameter }\end{array}$ & $\begin{array}{c}\text { 品种 } \\
\text { Cultivar }\end{array}$ & $\begin{array}{c}\text { 环境 } \\
\text { Environment }\end{array}$ & $\begin{array}{l}\text { 误差 } \\
\text { Error }\end{array}$ \\
\hline 籽粒硬度 Kernel hardness & $111.60^{* *}$ & 1.00 & 10.90 \\
\hline 灰分 Ash & 0.02 & 0.04 & 0.02 \\
\hline 籽粒蛋白 Kernel protein & $0.51^{* *}$ & $0.54^{* *}$ & 0.08 \\
\hline 面粉蛋白 Flour protein & $0.69^{* *}$ & $1.03^{* *}$ & 0.14 \\
\hline 湿面筋 Wet gluten & $4.65^{* *}$ & $3.55^{*}$ & 0.78 \\
\hline 沉淀值 Sedimentation & $113.68^{* *}$ & $9.49^{*}$ & 1.77 \\
\hline 峰值时间 Peak time & $0.49^{* *}$ & $0.33^{* *}$ & 0.04 \\
\hline 峰值高度 Peak value & 9.03 & 8.11 & 8.62 \\
\hline 衰落角 Right of peak slope & 0.67 & 0.07 & 0.51 \\
\hline 8 分钟带宽 TimeX & $1.96^{* *}$ & 1.01 & 0.47 \\
\hline 水溶剂保持力 Water SRC & $5.91^{* *}$ & $11.36^{* *}$ & 0.80 \\
\hline 碳酸钠溶剂保持力 Sodium carbonate SRC & $30.05^{* *}$ & $51.06^{* *}$ & 2.19 \\
\hline 乳酸溶剂保持力 Lactic acid SRC & $65.47^{* *}$ & $24.15^{* *}$ & 3.70 \\
\hline 蔗糖溶剂保持力 Sucrose SRC & $285.22^{* *}$ & $64.37^{*}$ & 14.12 \\
\hline 吸水率 Absorption & $1.56^{* *}$ & 0.42 & 0.23 \\
\hline 形成时间 Development time & $1.01^{*}$ & 0.32 & 0.38 \\
\hline 稳定时间 Stability & $6.90^{* *}$ & $3.01^{*}$ & 0.67 \\
\hline 弱化度 Weakness & $949.76^{* *}$ & 75.76 & 116.37 \\
\hline 峰值黏度 Peak viscocity & $61298.41^{* *}$ & $88961.27^{* *}$ & 11235.75 \\
\hline 低谷黏度 Through viscocity & $34840.77^{* *}$ & $40361.17^{* *}$ & 5331.82 \\
\hline 稀解值 Break down & $14300.75^{* *}$ & $9634.07^{*}$ & 2744.39 \\
\hline 最终黏度 Final viscocity & $87186.53^{* *}$ & $75102.27^{*}$ & 14811.95 \\
\hline 反弹值 Set back & $26011.55^{* *}$ & 5507.12 & 4451.84 \\
\hline 峰值时间 Peak time & $0.022^{*}$ & 0.008 & 0.008 \\
\hline 糊化温度 Pasting temperature & $28.14^{*}$ & 19.76 & 13.21 \\
\hline 可溶性谷蛋白聚合体 EPP & $1421.34^{* *}$ & 71.44 & 437.84 \\
\hline 不溶性谷蛋白聚合体 UPP & $528.05^{* *}$ & 518.47 & 186.30 \\
\hline 谷蛋白总量 Total glutenin protein & 1135.61 & 287.61 & 950.99 \\
\hline 醇蛋白总量 Total gliadin protein & $2307.44^{* *}$ & $2224.47^{*}$ & 549.30 \\
\hline 谷蛋白/醇溶蛋白 Glutenin/gliadin & $0.026^{* *}$ & $0.064^{* *}$ & 0.004 \\
\hline 不溶性谷蛋白聚合体百分含量 \%UPP & $0.003^{* *}$ & 0.001 & 0.0003 \\
\hline 饼干直径 Cookie diameter & $0.129^{* *}$ & $0.128^{*}$ & 0.023 \\
\hline 饼干厚度 Cookie thickness & $0.191^{* *}$ & 0.034 & 0.026 \\
\hline 直径/厚度 Diameter/Thickness & $0.661^{* *}$ & 0.140 & 0.080 \\
\hline
\end{tabular}

" 和 ${ }^{* *}$ 分别表示显著水平为 0.05 和 0.01 。

${ }^{*}$ and ${ }^{* *}$ indicated the significance at the 0.05 and 0.01 probability levels, respectively. 